\title{
2018: vientos favorables PARA EL CRECIMIENTO
}

Por Carlos J. García, Ph.D. en Economía, University of California (LA), EE.UU. Académico FEN UAH.

El nuevo gobierno del presidente Piñera enfrenta escenarios -externo e interno-favorables. El FMI proyecta un

crecimiento mundial de hasta $3.9 \%$ para el 2018, Chile no debiera crecer menos que esa cifra este año, incluso es muy posible por sobre un 4 por ciento.

$\mathrm{n}$ el escenario interno hay un elemento clave, aunque no asegurado, que empuja la economía por sobre el $4 \%$.

Las expectativas económicas tanto del consumo privado como de la inversión están desatadas. Por primera vez en muchos años, se siente esa fuerza detrás de la economía. Se puede polemizar sobre los efectos distributivos del nuevo gobierno, pero no en su sesgo pro crecimiento. Eso lo perciben los agentes como nunca y están dispuestos a dinamizar el gasto en todas sus dimensiones. Por algo los economistas conductuales han probado que gastar $y$ ganar dinero es adictivo y en Chile las condiciones están dadas para materializar esa adicción este año.

Si bien el sector privado ha estado a la altura de la recuperación, las políticas gubernamentales que están encargadas de la estabilización no. La política monetaria, como explicamos en ediciones anteriores, no bajó las tasas como debió hacerlo. Sin embargo, ya es tarde para llorar sobre la leche derramada, porque lamentablemente se perdió la oportunidad (jaunque cuesta aceptarla!). Pero bueno, si el Banco Central de Chile no bajó la tasa de interés esperemos que esta vez no la suba. Por esas cosas de la vida, en este momento no hacer nada es la política óptima para el país. En caso contrario, si el Banco Central se apura en subir las tasas, entonces arruinará las expectativas positivas. Esperemos que el nuevo consejo no yerre esta vez y la tasa de interés no suba este año. Total, debe hacer lo mismo que en los dos últimos años: nada y eso no es tan difícil.

Por otro lado, la política fiscal está enredada en una disputa entre economistas sobre el famoso Balance Cíclicamente Ajustado (BCA). Primero, una definición muy simple para aclarar este concepto, el BCA es una medida para saber si el gasto del gobierno está por encima o debajo de los ingresos más permanente (estructurales) de los ingresos tributarios. ¡Por eso, lo óptimo es que el BCA fuera cero! Así, en caso de una expansión, como la que se está materializando en estos meses, un BCA de cero aseguraría que los recursos del superávit fiscal se ahorren para aquellos años de bajo crecimiento económico. Esto en teoría, el problema es que en los últimos años el BCA ha sido persistentemente negativo (déficit) y con ello se gastó más de lo establecido en la regla fiscal y por lo tanto se acumuló deuda pública. Por eso Chile sufrió su primera caída en su clasificación de riesgo en 25 años: bajo crecimiento, más deuda y aumento en la vulnerabilidad externa.

¿Fue un error no cumplir con la regla fiscal? En principio no lo fue. Las razones son simples, el Banco Central no bajó nunca la tasa de interés y con ello no dejó más salida al gobierno de la ex presidenta Bachelet que sostener el magro crecimiento con más gasto público. Recordemos que la política macro en Chile funciona con los siguientes ingredientes: si el gobierno sigue la re-

"Una mejor coordinación entre Hacienda y el BC, más las buenas expectativas y el buen escenario externo, hará que Chile crezca bastante en los próximos dos años" gla fiscal y el tipo de cambio fluctúa libremente, entonces el principal encargado de estabilizar la economía es el Banco Central a través de la tasa de interés (tasa de política monetaria oTPM). En otras palabras, si el gasto de gobierno sigue una regla, el tipo de cambio flexible permite al $\mathrm{BC}$ tener autonomía para fijar, en teoría, la tasa de interés. ¿Por qué? Si el Central hubiera bajado la tasa de interés el peso se hubiera depreciado (el tipo de cambio habría subido) aún más. En caso contrario, con un tipo de cambio fijo, el aumento de la liquidez (por la caída de la tasa de interés) habría sido devuelta al Banco Central por una mayor demanda de dólares. La depreciación evita eso, la mayor liquidez se mantiene en la economía, pero al costo de un dólar más alto. Que en una situación deprimida no es un problema porque incentiva las exportaciones y con ello apura más la recuperación.

En favor del Banco Central de Chile el hecho que los gobiernos llevan incumpliendo el BCA desde el 2008. Sin duda que post crisis internacional, el mayor gasto de los años 2009-2010 no fue un error sino un completo éxito de la política fiscal que aseguró la estabilización de la economía chilena frente a una crisis mundial mayor, que por algo se conoce por la gran recesión. Los años posteriores, 2011-2014, se tendió a normalizar la política fiscal hacia un BCA de cero, situación que se revirtió completamente desde el 2015.

Sin duda que los últimos tres años de nuestra historia económica ha sido de un desencuentro total entre la política monetaria y fiscal. La falta de coordinación ha sido grave con una política monetaria que no tomó las riendas de la estabilización y un gobierno gastando fuerte. En otras palabras, si lo comparamos con las tareas de hacer una buena cena, nuestros chefs olvidaron sus recetas e ingrediente aprendidos en prestigiosas escuelas de cocina y cocinaron cualquier cosa, poniendo menos de lo que se necesitaba y más de lo que sobraba.

No es una solución, sin embargo, bajar abruptamente el gasto y cumplir a rajatabla el BCA. Por supuesto que no, pero sí establecer una meta creíble, en la medida que la recuperación económica se consolida y los ingresos fiscales aumentan, para normalizar la regla fiscal.

Menos discusión y más claridad de cómo volvemos a una meta de un BCA igual a cero por el bien de Chile. También una mejor coordinación entre Hacienda y Banco Central, con eso, más las buenas expectativas y el buen escenario externo, Chile crecerá bastante en los próximos dos años. $\mathbf{E}$

Observatorio Económico

Decano: Jorge Rodríguez Grossi

Fono Facultad: 28897366

fen.uahurtado.cl 